\title{
ĐÁNH GIÁ PHƯƠNG PHÁP GIẢNG DẠY VÀ KIỀM TRA ĐÁNH GIÁ CHƯƠNG TRÌNH ĐÀO TẠO KHÓA 2018-2021 - CHƯƠNG TRÌNH QUẢN LÝ TÀI NGUYÊN VÀ MÔI TRƯỜNG
}

\author{
Nguyễn Thị Xuân Hạnh ${ }^{(*)}$, Bùi Phạm Phương Thanh ${ }^{(*)}$ \\ (*) Thạc sĩ. Truờng Đại học Thủ Dầu Một.Email: hanhntx@tdmu.edu.vn.
}

DOI: $10.37550 /$ tdmu.CFR/2021.01.133

\section{Tóm tắt}

Một chương trình đào tạo được thiết kế có các khóa học kiến thức chuyên ngành hố trợ lẫn nhau, có một kế hoạch rõ ràng trong việc tích hợp các kỹ năng cá nhân và giao tiếp, và kỹ năng kiến tạo sản phẩm, quy trình và hệ thống là vấn đề cốt lõi của tiêu chuẩn 3 CDIO - Chwơng trình đào tạo tích hợp. Sự cần thiết phải phân tích chuơng trình học được thù̀a nhận và gán ban đầu các kiến thức, kỹ năng và thái độ vào chuẩn đầu ra môn học. Do đó, bài viết này các tác giả sủ dụng chuoong trình đào tạo khóa 2018-2021 của chuong trình Quản lý tài nguyên và Môi trương làm ví du cu thể về việc đánh giá tổ hợp giữa phuơng pháp giảng dạy và phuơng pháp kiểm tra đánh giá. Việc đánh giá tổ hợ này được duy trì mối hai năm đề tù đó có sụ điều chinh cần thiết cho các churong trình đào tạo trong tuoong lai.

Tù̀ khóa: Đề xuớng CDIO, Chuẩn đầu ra, Chuơng trình đào tạo, phương pháp giảng dạy, kiểm tra đánh giá.

\section{1. Đặt vấn đề}

Hiện nay, trong giáo dục bậc đại học thì một chương trình đào tạo không thể được duy trì liên tục hết các khóa học này đến khóa học khác, việc duy trì sẽ làm lạc hậu kiến thức, đi sau thời đại và cực kỳ ảnh hưởng đến việc đào tạo sinh viên ra trường có việc làm lập tức và phù hợp chuyên ngành. Tại chương trình Quản lý tài nguyên và môi trường thì định kỳ 2 năm khi chương trình đào tạo hiện hành đang áp dụng, thì chương trình Quản lý tài nguyên và môi trường sẽ tiến hành rà soát thông qua cuộc họp giữa các giảng viên trong chương trình, giữa các chuyên gia ngoài trường tạm gọi tắt là các bên liên quan có chuyên môn để từ đó có các định hướng phù hợp trong việc xây dựng chương trình đào tạo mới trong tương lai. Các bên liên quan sẽ gồm giảng viên trong và ngoài trường, doanh nghiệp, sở ban ngành, các viện, trường đại học có sử dụng nguồn lao động chuyên ngành Quản lý tài nguyên và môi trường. 


\section{Nội dung và kết quả đánh giá tổ hợp chương trình đào tạo}

\subsection{Phưong pháp giảng dạy}

Chương trình đa dạng hóa các phương pháp giảng dạy, vận dụng phương pháp giảng dạy hòa hợp, tích cực; học tập trực tuyến E-learning, tăng cường trải nghiệm thực tế, kiến tập, thực tập. Cụ thể: thuyết giảng hiện đại, seminar, bài tập nhóm, tự học, thí nghiệm, thực hành tại doanh nghiệp, ứng dụng E-learning, ứng dụng nghiên cứu khoa học.

Bảng 1. Các phương pháp giảng dạy ứng với các khối kiến thức và các học phần

\begin{tabular}{|c|c|c|}
\hline $\begin{array}{l}\text { Khối kiến } \\
\text { thức }\end{array}$ & Học phần & Phương pháp giảng dạy \\
\hline \multirow[t]{5}{*}{ Đại cương } & $\begin{array}{l}\text { Những nguyên lý cơ bản của chủ nghĩa Mác - Lênin } \\
(5+0) \text {; Tư tường Hồ Chí Minh }(2+0) \text {; Đường lối CM Đảng } \\
\text { CS VN }(3+0)\end{array}$ & $\begin{array}{l}\text { Thuyết giảng hiện đại, thuyết } \\
\text { trình, bài tập nhóm, ứng dụng } \\
\text { E-learning }\end{array}$ \\
\hline & Toán cao cấp A1 (1+1) & Thuyết giảng hiện đại, bài tập \\
\hline & Tư duy biện luận - sáng tạo (3+0) & $\begin{array}{l}\text { Thuyết giảng hiện đại, bài tập } \\
\text { nhóm }\end{array}$ \\
\hline & $\begin{array}{l}\text { Nhập môn nghiên cứu khoa học }(1+1) \text {; Quản lý học đại } \\
\text { cương }(2+0)\end{array}$ & $\begin{array}{l}\text { Thuyết giảng hiện đại, thuyết } \\
\text { trình, bài tập nhóm, bài tập thực } \\
\text { hành }\end{array}$ \\
\hline & $\begin{array}{l}\text { Quản lý dự án }(1+1) \text {; Đổi mới, sáng tạo và khởi nghiệp } \\
(2+0)\end{array}$ & $\begin{array}{l}\text { Thuyết giảng hiện đại, thuyết } \\
\text { trình, bài tập nhóm, thực hiện } \\
\text { dự án }\end{array}$ \\
\hline \multirow[t]{2}{*}{$\begin{array}{ll}\text { Cơ sở } \\
\text { ngành }\end{array}$} & $\begin{array}{l}\text { Nhập môn ngành quản lý tài nguyên và môi trường }(2+1) \text {; } \\
\text { Phương pháp NCKH chuyên ngành }(1+1)\end{array}$ & $\begin{array}{l}\text { Thuyết giảng hiện đại, bài tập } \\
\text { nhóm, bài tập thực hành }\end{array}$ \\
\hline & $\begin{array}{l}\text { Khoa học đất }(2+0) \text {; Sinh thái học }(2+0) \text {; Phân tích hệ } \\
\text { thống môi trường }(2+0) \text {; Quy hoạch môi trường }(2+0) \text {; } \\
\text { Kiểm soát ô nhiểm môi trường }(2+0) \text {; An toàn lao động } \\
\text { VSMT }(2+0) \text {; Quy hoạch sử dụng đất }(2+0) \text {; Biến đồi khí } \\
\text { hậu }(2+0) \text {; Sức khỏe và an toàn môi trường (HSE) }(2+0) \text {; } \\
\text { Công nghệ sinh học môi trường }(2+0) \text {; Công nghệ xử lý } \\
\text { nước thải }(2+0) \text {; }\end{array}$ & $\begin{array}{l}\text { Thuyết giảng hiện đại, thuyết } \\
\text { trình, bài tập nhóm }\end{array}$ \\
\hline \multirow[t]{4}{*}{$\begin{array}{l}\text { Cơ sở } \\
\text { ngành }\end{array}$} & $\begin{array}{l}\text { Mô hình hóa môi trường }(2+0) \text {; Quan trắc môi trường } \\
(2+0) \text {; Các PP thống kê MT }(2+0) \text {; Thủy lực môi trường } \\
(2+0) \text {; Luật và chính sách } \mathrm{MT}(2+0) \text {; Vi sinh môi trường } \\
(2+0) \text {; Đại cương công nghệ môi trường }(2+0) \text {; Hóa môi } \\
\text { trường }(2+0) \text {; Hóa phân tích }(2+0) \text {; Cơ sở hệ thống thông } \\
\text { tin địa lý }(2+0)\end{array}$ & $\begin{array}{l}\text { Thuyết giảng hiện đại, thuyết } \\
\text { trình, bài tập nhóm }\end{array}$ \\
\hline & Vẽ kỹ thuật và Autocad $(2+0)$; Cơ sở viễn thám $(2+0)$ & $\begin{array}{l}\text { Thuyết giảng hiện đại, bài tập } \\
\text { nhóm }\end{array}$ \\
\hline & $\begin{array}{l}\text { TH vẽ kỹ thuật và Autocad }(0+1) \text {; TH cơ sở viễn thám } \\
(0+1) \text {; TH cơ sở hệ thống thông tin địa lý }(0+1)\end{array}$ & $\begin{array}{l}\text { Thuyết giảng hiện đại, ứng } \\
\text { dụng CNTT }\end{array}$ \\
\hline & TH hóa phân tích (0+1) & Thực hành, thí nghiệm \\
\hline $\begin{array}{l}\text { Chuyên } \\
\text { ngành }\end{array}$ & $\begin{array}{l}\text { Đánh giá rủi ro MT }(1+1) \text {; Phân tích MT }(2+0) \text {; Quản lý } \\
\text { tài nguyên nước }(1+1) \text {; Quản lý tổng hợp biển và đới bờ } \\
(1+1) ; \text { ISO } 14001(2+0) \text {; Sản xuất sạch hơn }(1+1) \text {; Kinh tế } \\
\text { TN và MT }(2+0) \text {; Quản lý tồng hợp lưu vực }(1+1) \text {; Độc } \\
\text { học MT }(2+0) \text {; Năng lượng và phát triển bền vững }(1+1) \text {; }\end{array}$ & $\begin{array}{l}\text { Thuyết giảng hiện đại, thuyết } \\
\text { trình, bài tập nhóm, bài tập thực } \\
\text { hành }\end{array}$ \\
\hline
\end{tabular}




\begin{tabular}{|c|c|c|}
\hline & $\begin{array}{l}\text { Công nghệ xanh }(2+0) \text {; Quản lý tài nguyên rừng và đa } \\
\text { dạng sinh học }(1+1) \text {; Quản lý CTR và chất thải nguy hại } \\
(2+0) \text {; Quản lý MT không khí và tiếng ồn }(1+1)\end{array}$ & \\
\hline \multirow[t]{6}{*}{$\begin{array}{l}\text { Chuyên } \\
\text { ngành }\end{array}$} & $\begin{array}{l}\text { Thực hành phân tích môi trường }(0+1) ; \mathrm{Kỹ} \text { thuật lấy mẫu } \\
\text { và xử lý mẫu }(0+2)\end{array}$ & Thực hành, thí nghiệm \\
\hline & Quản lý tài nguyên khoáng sản và năng lượng (1+1) & $\begin{array}{l}\text { Thuyết giảng hiện đại, thuyết } \\
\text { trình, bài tập nhóm, thực hiện } \\
\text { dự án }\end{array}$ \\
\hline & $\begin{array}{l}\text { Quản lý môi trường đô thị và khu công nghiệp }(1+1) \text {; } \\
\text { Đánh giá tác động môi trường }(1+1)\end{array}$ & $\begin{array}{l}\text { Thuyết giảng hiện đại, thuyết } \\
\text { trình, bài tập, đi thực tế }\end{array}$ \\
\hline & $\begin{array}{l}\text { Úng dụng GIS trong QLTN\&MT }(0+2) \text {; Úng dụng Viễn } \\
\text { thám trong QLTN\&MT }(0+2) \text {; Úng dụng mô hình hóa } \\
\text { trong QLTN\&MT }(0+2)\end{array}$ & $\begin{array}{l}\text { Thuyết giảng hiện đại, ứng } \\
\text { dụng CNTT }\end{array}$ \\
\hline & $\begin{array}{l}\text { TH quản lý CTR và chất thải nguy hại }(0+1) \text {; TH xây } \\
\text { dựng ISO } 14001(0+1)\end{array}$ & Bài tập nhóm, đi thực tế \\
\hline & $\begin{array}{l}\text { Thực tập } 1(0+2) \text {; Thực tập } 2(0+4) \text {; Thực tập tốt nghiệp } \\
(0+6) \text {; Khóa luận tốt nghiệp/Báo cáo tốt nghiệp }(0+5)\end{array}$ & Thực hành tại doanh nghiệp \\
\hline
\end{tabular}

\subsection{Phương pháp kiểm tra đánh giá}

Phương pháp kiểm tra đánh giá có sự liên kết đánh giá - giảng dạy - học tập hướng đến chuẩn đầu ra, cụ thể:

Bảng 2. Phương pháp kiểm tra đánh giá

\begin{tabular}{|c|c|c|}
\hline $\begin{array}{l}\text { Khối kiến } \\
\text { thức }\end{array}$ & Học phần & $\begin{array}{l}\text { Phương pháp } \\
\text { kiểm tra đánh } \\
\text { giá }\end{array}$ \\
\hline \multirow[t]{4}{*}{ Đại cương } & $\begin{array}{l}\text { Những nguyên lý cơ bản của chủ nghĩa Mác - Lênin }(5+0) \text {; Tư tưởng } \\
\text { Hồ Chí Minh }(2+0) \text {; Đường lối CM Đảng CS VN }(3+0)\end{array}$ & Trắc nghiệm \\
\hline & Toán cao cấp A1 (1+1); Tư duy biện luận - sáng tạo (3+0) & Tự luận \\
\hline & Nhập môn nghiên cứu khoa học (1+1); Quản lý học đại cương (2+0) & Tiểu luận \\
\hline & Quản lý dự án (1+1); Đổi mới, sáng tạo và khởi nghiệp (2+0) & Dự án \\
\hline \multirow[t]{5}{*}{ Cơ sở ngành } & Sinh thái học $(2+0)$; Cơ sở viễn thám $(2+0)$ & Trắc nghiệm \\
\hline & $\begin{array}{l}\text { Vẽ kỹ thuật và Autocad }(2+0) \text {; Kiểm soát ô nhiễm môi trường }(2+0) \text {; } \\
\text { Hóa phân tích }(2+0) \text {; Mô hình hóa môi trường }(2+0) \text {; Các PP thống kê } \\
\text { MT }(2+0) \text {; Thủy lực môi trường }(2+0) \text {; Luâât và chính sách MT }(2+0) ; \\
\text { Vi sinh môi trường }(2+0) \text {; Sức khỏe và an toàn môi trường (HSE) } \\
(2+0) \text {; Công nghệ sinh học môi trường }(2+0)\end{array}$ & Tự luận \\
\hline & $\begin{array}{l}\text { Nhập môn ngành quản lý tài nguyên và môi trường }(2+1) \text {; Phương } \\
\text { pháp NCKH chuyên ngành }(1+1) \text {; Đại cương công nghệ môi trường } \\
(2+0) \text {; Khoa học đất }(2+0) \text {; Hóa môi trường }(2+0) \text {; Phẩ tích hệ thống } \\
\text { môi trường }(2+0) \text {; Quy hoạch môi trường }(2+0) \text {; Cơ sở hệ thống thông } \\
\text { tin địa lý }(2+0) \text {; Quan trắc môi trường }(2+0) \text {; An toàn lao động VSMT } \\
(2+0) \text {; Quy hoạch sử dụng đất }(2+0) \text {; Biến đổi khí hậu }(2+0) \text {; Công } \\
\text { nghệ xử lý nước thải }(2+0)\end{array}$ & Tiểu luận \\
\hline & $\begin{array}{l}\text { TH vẽ kỹ thuật và Autocad }(0+1) \text {; TH cơ sở viễn thám }(0+1) \text {; TH cơ } \\
\text { sở hệ thống thông tin địa lý }(0+1)\end{array}$ & $\begin{array}{l}\text { Thực hành trên } \\
\text { máy }\end{array}$ \\
\hline & TH hóa phân tích $(0+1)$ & Thí nghiệm \\
\hline Chuyên ngành & Đánh giá rủi ro môi trường $(1+1)$; Đánh giá tác động môi trường & Tự luận \\
\hline
\end{tabular}




\begin{tabular}{|c|c|}
\hline $\begin{array}{l}(1+1) \text {; Kinh tế tài nguyên và môi trường }(2+0) \text {; Quản lý } C T R \text { và chất } \\
\text { thải nguy hại }(2+0) \text {; Độc học môi trường }(2+0)\end{array}$ & \\
\hline Quản lý tổng hợp biển và đới bờ $(1+1)$ & Vấn đáp \\
\hline $\begin{array}{l}\text { Phân tích môi trường }(2+0) \text {; Quản lý tài nguyên nước }(1+1) \text {; ISO } \\
14001(2+0) \text {; Sản xuât sạch hơn }(1+1) \text {; Quản lý tổng hợp lưu vực } \\
(1+1) \text {; Năng lượng và phát triển bền vững }(1+1) \text {; Công nghệ xanh } \\
(2+0) \text {; Quản lý tài nguyên rừng và đa dạng sinh học }(1+1) \text {; Quản lý } \\
\text { môi trường đô thị và khu công nghiệp }(1+1) \text {; Quản lý môi trường } \\
\text { không khí và tiếng ồn }(1+1) \text {; Ứng dụng GIS trong QLTN\&MT }(0+2)\end{array}$ & Tiểu luận \\
\hline Quản lý tài nguyên khoáng sản và năng lượng $(1+1)$ & Dự án \\
\hline TH phân tích môi trường $(0+1)$; Kỹ thuật lấy mẫu và xử lý mẫu $(0+2)$ & Thí nghiệm \\
\hline $\begin{array}{l}\text { Úng dụng Viễn thám trong QLTN\&MT }(0+2) \text {; Úng dụng mô hình hóa } \\
\text { trong QLTN\&MT }(0+2)\end{array}$ & $\begin{array}{l}\text { Thực hành trên } \\
\text { máy }\end{array}$ \\
\hline $\begin{array}{l}\text { TH quản lý CTR và chất thải nguy hại (0+1); TH xây dựng ISO } 14001 \\
(0+1)\end{array}$ & Báo cáo \\
\hline $\begin{array}{l}\text { Thực tập } 1(0+2) \text {; Thực tập } 2(0+4) \text {; Thực tập tốt nghiệp }(0+6) \text {; Khóa } \\
\text { luận tốt nghiệp/Báo cáo tốt nghiệp }(0+5)\end{array}$ & Báo cáo \\
\hline
\end{tabular}

Việc đánh giá tổ hợp giữa phương pháp giảng dạy và phương pháp kiểm tra đánh giá rất quan trọng trong triển khai giảng dạy và kiểm tra kết thúc một học phần. Chúng ta xem học phần đó dùng phương pháp nào giảng dạy, và bước tiếp đến là phân tích phương pháp giảng dạy đó có phù hợp với môn học hay không. Nếu là môn cơ sở ngành thì nên dùng phương pháp nào giảng dạy, và nếu là môn chuyên ngành thì phương pháp nào sẽ phù hợp hơn. Tương tự thì ở phần kiểm tra đánh giá chúng ta dùng phương pháp nào đánh giá, phương pháp đó có phù hợp, có khai thác hết tư duy và khả năng diễn giải vấn đề của sinh viên hay không. Từ đó chúng ta sẽ lựa chọn và tìm ra phương pháp kiểm tra đánh giá phù hợp với từng giai đoạn của học phần.

Mặt khác, sau khi đánh giá tổ hợp chương trình đào tạo thì các giảng viên trong Chương trình sẽ cùng ngồi lại với nhau, phân tích kết quả, đưa ra các yêu cầu, các điều chỉnh, nhằm góp ý cho giảng viên lựa chọn phương pháp giảng dạy phù hợp, thiết kế bài giảng phù hợp và triển khai đánh giá phù hợp với học cho các chương trình đào tạo sau và các học kỳ sau.

\section{Kết quả}

Đối với phương pháp giảng dạy: Chương trình đào tạo kết hơp phong phú nhiều phương pháp để gia tăng tính linh hoạt, mới mẻ và hứng thú cho sinh viên như: thuyết giảng, thực hành trên máy, E-learning, bài tập nhóm, thuyết trình nhóm, đi thực tế, thực hành doanh nghiệp... Việc áp dụng nhiều phương pháp cùng lúc có nhiều ý nghĩa tích cực như: Không phải sinh viên nào cũng thuận lợi tiếp thu bằng phương pháp làm việc nhóm, nếu chúng ta sử dụng hoàn toàn một phương pháp làm việc nhóm sẽ gây khó khăn cho nhóm sinh viên này. Một ý nghĩa khác đó là ở các học phần khác nhau sẽ có thể cần thiết có các phương pháp truyền đạt khác nhau thì sẽ dễ dàng truyền tải đầy đủ thông tin của học phần đó. Đối với phương pháp kiểm tra đánh giá: Chương trình đạo tạo cùng lúc sử dụng 
nhiều phương pháp kiểm tra đánh giá như: trắc nghiệm, vấn đáp, tự luận, tiểu luận, thực hành trên mày, thực hành thực tế và đồ án. Các phương pháp kiểm tra đánh giá sẽ được lựa chọn phù hợp cho từng môn học của chương trình. Tóm lại, trong chương trình đào tạo các học phần với kiến thức chuyên ngành hỗ trợ lẫn nhau, có một kế hoạch rõ ràng trong việc tích hợp các kỹ năng cá nhân và giao tiếp, và kỹ năng kiến tạo sản phẩm, quy trình và hệ thống đáp ứng tiêu chuẩn 3 - Chương trình đào tạo tích hợp của đề xướng CDIO.

\section{Kết luận}

Định kỳ sau một thời gian đào tạo là 2 năm, Chương trình phải ngồi để rà soát tìm ra các học phần không còn phù hợp, bổ sung các học phần đang được các bên liên quan đánh giá cao và phù hợp với xu thế việc làm cho sinh viên các khóa sau này...

Hiệu chỉnh lại chương trình đào tạo còn giúp chương trình hiệu chỉnh lại chuẩn đầu ra dựa trên chương trình đào tạo mới. Công việc này chúng tôi làm quy trình ngược vì lý do chúng tôi đã có chương trình đào tạo đang vận hành, chúng tôi chỉ rà soát sửa chữa chứ không đập bỏ và xây dựng mới hoàn toàn.

Chương trình đào tạo tích hợp cần hội đủ các tiêu chí: kiến thức chuyên môn, kỹ năng mềm và thái độ. Chuẩn đầu ra cụ thể sẽ được xây dựng dựa theo thang Bloom. Chúng sẽ đóng vai trò quan trọng như là dữ liệu đầu vào trong việc xây dựng và triển khai khung chương trình đào tạo tích hợp cũng như đề cương chi tiết cho từng học phần cụ thể. Mặc dù sau đó chúng còn trải qua việc xây dựng đề cương chi tiết cho từng học phần cụ thể đến ít nhất là mức độ 3 theo đề cương CDIO. Tuy nhiên, quá trình xây dựng chuẩn đầu ra hoàn chỉnh như là người chỉ đường cho việc hiệu chỉnh và xây dựng đề cương làm theo đề xướng CDIO phát huy được tác dụng để nâng cao chất lượng đào tạo trong điều kiện thực tế tại Chương trình Quản lý tài nguyên và môi trường.

\section{Tài liệu tham khảo}

[1] Hồ Tấn Nhựt. Đoàn Thị Minh Trinh., "Cải cách và xây dựng chương trình đào tạo kỹ thuật theo phương pháp tiếp cận CDIO”, Nhà xuất bản Đại học Quốc gia Thành Phố Hồ Chí Minh, Vol.1, 2010, pp 239-244.

[2] Đoàn Thị Minh Trinh. Nguyễn Hội Nghĩa., "Hướng dẫn thiết kế và phát triển chương trình đào tạo đáp ứng chuẩn đầu ra”, Nhà xuất bản Đại học Quốc Gia Tp.HCM, 2014.

[3] Kỷ yếu Hội nghị CDIO toàn quốc., "Đào tạo đáp ứng nhu cầu xã hội và hội nhập quốc tế”, Đại Học Quốc Gia Thành Phố Hồ Chí Minh, 2012.

[4] Kỷ yếu Hội thảo cấp trường., "Xây dựng chuẩn đầu ra ngành Sư phạm Lịch Sử và Sư phạm Địa Lý theo hướng tiếp cận CDIO-Nhu cầu và giải pháp”, 2016. 